\title{
The Lived Experience of Recovery: The Role of Health Work in Addressing the Social Determinants of Mental Health
}

\author{
Colleen Reid \\ Douglas College \\ Nancy Clark \\ University of Victoria \\ Ania Landy \\ University of British Columbia \\ Maya Alonso \\ Open Door Group Services Society
}

\begin{abstract}
Recovery is a policy framework for mental health in Canada. Key challenges to the integration of recovery include a gap in knowledge about the work that people do to promote their health and well-being in the context of living with mental ill health. This study used Photovoice to explore the lived realities of people living with mental ill health and the impact of the social determinants on their recovery process. Findings from this study inform policy and practice on promoting health work as an important dimension of recovery and community inclusion.
\end{abstract}

Keywords: health work, recovery, social determinants of health, mental health, community inclusion, Photovoice

Colleen Reid, Therapeutic Recreation, Douglas College, Coquitlam, British Columbia; Nancy Clark, Nursing, University of Victoria, Victoria, British Columbia; Ania Landy, Nursing, University of British Columbia, Vancouver, British Columbia; and Maya Alonso, Thrive Program, Open Door Group Services Society, Vancouver, British Columbia.

This research was supported by grants from the Vancouver Foundation.

Correspondence concerning this article should be addressed to Colleen Reid, Department of Therapeutic Recreation, Douglas College, 1250 Pinetree Way, Coquitlam BC V3B 7X3. Email: reidc@douglascollege.ca 


\section{RÉSUMÉ}

Le rétablissement est un enjeu pour la politique de santé mentale au Canada. Parmi les défis importants de l'intégration du rétablissement, on note le manque d'information quant aux efforts que doivent faire les gens aux prises avec une maladie mentale pour promouvoir leur santé et leur bien-être. Cette étude utilise la méthode Photovoice pour explorer les réalités que vivent ces personnes et l'incidence des déterminants sociaux sur leur processus de rétablissement. Les résultats de cette étude devraient permettre d'orienter les politiques et les pratiques en santé concernant la dimension importante du rétablissement et de l'inclusion communautaire.

Mots clés : travail de santé, rétablissement, déterminants sociaux, santé mentale, inclusion communautaire, Photovoice

Individuals living with mental illness disproportionately experience health disparities as a result of deficits in the social determinants of health, including poverty and lack of social support, that result in social exclusion, stigma, and racism (Belle-Isle, Benoit \& Pauly, 2014; Burns, Tomita, \& Kapadia, 2014; Karban, 2017; Mental Health Commission of Canada [MHCC], 2016; Pauly, Carlson, \& Perkin, 2012; World Health Organization, 2014). In Canada and elsewhere the recovery movement emerged in the 1990s in response to deinstitutionalization, critiques of psychiatrization, and the identification of sanism as a form of discrimination (Karban, 2017; Morrow \& Weisser, 2012). Recovery is a subjective process that involves individual, as well as social and material factors (Borg \& Davidson, 2008; Borg, Karlsson, Tondora, \& Davidson, 2009; Mezzina et al., 2006; Schön, Denhov, \& Topor, 2009; Tew et al., 2012; Topor, Borg, Di Girolamo, \& Davidson, 2011; Topor et al., 2006). Many mental health policies have embraced recovery as a framework but have failed to fully integrate the social determinants of mental health (MHCC, 2016). This has resulted in overlooking the ways in which social determinants of health intersect with mental illness to produce experiences of oppression and marginalization as well as a lack of knowledge about the lived realities of people with lived experience of mental illness. Consequently inconclusive, limited, and de-contextual understandings of recovery are perpetuated (Karban, 2017; Morrow \& Weisser, 2012; Webb, 2012).

In the research study Imagining Inclusion we explored experiences of community inclusion, health and well-being for diverse individuals living with a mental illness. Our research question was: How do individuals living with mental illness experience community inclusion, health, and well-being? We learned about individuals' multiple, ongoing, lifelong, and precarious efforts to maintain health and well-being. In order to understand research participants' varied and ongoing efforts to manage their mental illness, we applied and reconceptualized the concept of health work to analyze participants' lived experiences of recovery by exposing the day-to-day effort, or work, of living with a mental illness and by examining the profound impact of the social determinants of mental health on people's recovery processes. 


\section{LITERATURE REVIEW}

\section{The Social Determinants of Mental Health}

Mental health and many common mental disorders are shaped by the social, economic, and physical environments in which people live (WHO, 2014). Social determinants of mental health are shaped by inequalities related to housing, education, employment, welfare, to name a few. There is a need to address risk and protective factors for mental health across different levels of healthcare services and social policy (MHCC, 2016; WHO, 2014). The experience of mental illness is mediated by an individual's immediate physical and social settings, the institutions with which they interact, and their culture (Barnett \& Casper, 2001). People's experience of mental illness intersects with health determinants to produce social exclusion and marginalization (Karban, 2017; Weisser, Morrow, \& Jamer, 2011). According to Fisher and Baum (2010), research in developed countries demonstrates a social gradient of health where physical and mental health deteriorate in "lowest" status groups and is dependent upon multiple social determinants of health such as socioeconomic status, gender, ethnicity, and culture. Karban (2017) describes how downstream micro-level factors experienced at the individual level intersect with upstream factors at the macro level such as social and economic environments, to shape recovery and what people are able to do to stay well.

The social determinants of mental health are highly relevant to lived experience of people with mental illness given the risk associated with increased exposure to stress incurred by various levels of social disadvantage (Fisher \& Baum, 2010). The Mental Health Commission of Canada (MHCC, 2009, 2012, 2016a, 2016 b 2019) has instituted a call to action to redress ongoing stigma and discrimination that negatively affect and socially exclude people with lived experiences of mental illness based on their ethnic identity, gender, ability, education, and economic status. The MHCC's (2009, 2012, 2016a, 2016b, 2019) calls to action include recovery-oriented practices to take on an active role in addressing the determinants of health and reducing health disparities in order to promote mental health and well-being of all peoples. This call is incorporated in guidelines which highlight hope, dignity, and inclusion as part of recovery-oriented practice (Chodos, d'Auteuil, Martin, \& Raymond, 2015). Although contextualizing recovery in the contexts of the broader social determinants of health can foster and build effective community mental health policy and practice, few inroads have been made to address the social determinants of mental health for people with lived experience of mental illness (Morrow \& Weisser, 2012).

\section{The Recovery Movement and Recovery-Oriented Practice}

The concepts of recovery and recovery-oriented practice have become central in the mental health field. At its roots, the recovery model is intended to validate consumer or survivor expertise over professional control in order to mitigate broader processes of exclusion and dominance of biomedical approaches to mental health (Anthony, 1993; Hyde, Bowles, \& Pawar, 2015; Karban, 2017; Morrow \& Weisser, 2012; Weisser et al., 2011). While a cornerstone of the MHCC strategy is the urgent need to integrate and analyze recovery from the perspective of those with lived experience (Chodos et al., 2015; Lucock et al., 2011) a gap in knowledge exists on the social determinants of mental health and their impact on individual lived realities (Hyde et al., 2015; Luckock et al., 2011; Morrow \& Weisser, 2012). In response to the limited evidence about the role that the social determinants of mental health play in the day-to-day lives of people 
living with mental illness, this study addresses individuals' experiences of inclusion and the work they do to address the social determinants shaping their health and well-being.

What stymies concrete action on the social determinants of mental health are the unclear yet lofty approaches, models, philosophies, paradigms, movements, and visions of recovery (Davidson, Lawless, \& Leary, 2005; Roberts \& Wolfson, 2004). McWade (2016) argues that recovery is not one thing with multiple meanings. Rather, different practices bring different "enactments" of recovery into existence, and not all enactments of recovery are equal. Since recovery is multiple, certain enactments of recovery will marginalize or obscure others depending upon the context (McWade, 2016). The current enactment of recovery through recovery-oriented practice emphasizes teaching and practicing personal skills which prioritizes an individualistic "personal journey" but also reinforces personal responsibility for one's mental health. This can further marginalize other dimensions and experiences of recovery including attention to the social determinants of mental health and place added burdens on people already engaged in health work (May et al., 2014). It also negates the possibility of having good mental health while living with a mental illness (Provencher \& Keyes, 2011).

The dominant discourse of recovery fails to attend to social structures which produce, and in some respects reinforce, marginalization and stigmatization of mental illness (Howell \& Voronka, 2012; McWade, 2016; Morrow, 2013; Rose, 2014). In reality, individual disparities intersect with broader social and structural processes to shape illness and wellness trajectories. Weiser et al. (2011) argue that what is missing is the recognition of structural barriers and their impact on inequalities based on race, gender, class, sexuality, and other intersecting determinants. This has led some to criticize recovery models for reinforcing structural barriers to mental health, including racism, sexism, classism, ableism, and homophobia (Hyde et al., 2015; Morrow \& Weisser, 2012; Rossiter \& Morrow, 2011). Additionally, some are sceptical of recovery models because, in the context of British Columbia, they have coincided with funding cuts to mental health services thus offloading responsibility from the mental health system to individuals (Wilton, 2004).

\section{Health Work: The Lived Experience of Recovery}

Although mental health policy and practice have adopted recovery as a framework, the daily effort, or work, of living with a mental illness and the profound impact of the social determinants on mental health and on lived experiences of mental illness have remained invisible. In the current study research participants who were active in the data analysis process critiqued the limitations of the recovery framework. Although the term health work was coined several decades ago, in our case the concept of health work-or doing work to manage illness or stay well - emerged from the collaborative data analysis process as the most appropriate and meaningful conceptual framework that captured the daily effort and process for managing the social determinants of health of participants living with a mental illness. As such, health work was used as the conceptual framework guiding this analysis.

The concept of health work has received little attention in the mental health and recovery literature due to the lack of recognition of the unpaid work that individuals do to maintain, promote, and prevent ill health. Concepts such as self-management and self-care have been used to describe strategies to manage illness experience; however, there are things people do to stay well beyond symptom management and being 
gainfully employed that go unrecognized (Karban, 2017; Lucock et al., 2011). As well, some conceptions of self-management and self-care are not rooted in the lived experiences and broader health determinants that profoundly shape the lives of people with mental illness.

Understanding health work as integral to the lived experience of recovery can shift the focus on individual accountability to shared decision making and shared power by dispelling common stigmas of mental illness and by recognizing individuals' agency in promoting their mental health and well-being within the context of mitigating processes of social exclusion. As originally conceptualized, the concept of health work came out of the Developmental Health Model and was used "to help clinicians and researchers develop basic knowledge about the nature of healthy living as seen through the eyes of clients, their families, and significant others, and the role of nurses in facilitating this process" (Burrill, 1998, p. 6). Ford-Gilboe (1997) later conceptualized health work on a continuum that ranged from lower to higher degrees. Lower degrees of health work were characterized by a lack of conscious thought about health, choosing established health routines over new ideas, and a tendency to base health choices on expert opinion or default. In contrast, higher degrees of health work were associated with reflective and active involvement in health matters such as looking for alternative choices for promoting and maintaining health and making health decisions using a problem-solving approach (Ford-Gilboe, 1997).

Our adoption of the concept of health work builds upon these foundations and aims to contextualize individual lived realities that intersect with micro and macro processes of recovery (Karban, 2017). We define health work as the daily effort involved in the recovery process that is shaped by societal, systemic, and individual factors.

\section{RESEARCH CONTEXT AND METHODS}

Community-based participatory research (CBPR) was used to increase understanding of how the social determinants of mental health played out in the lived realities of people with mental illness. CBPR is "research rooted in community, serving community interests, encouraging citizen participation and geared towards affecting social change" (Flicker, Savan, McGrath, Kolenda, \& Mildenberger, 2008, p. 241). As a research methodology CBPR puts the voices and experiences of people with lived experience of the social issue under study at the centre of the research process (Reid, Brief, \& LeDrew, 2009; Reid \& Brief, 2009). CBPR promotes social justice in research processes as well as in outcomes (Foster-Fishman, Nowell, Deacon, Nievar, \& McCann, 2005; Hergenrather, Rhodes, Cowan, Bardhoshi, \& Pula, 2009).

Photovoice is one example of a CBPR approach. It promotes a critical dialogue for discussing strengths, problems, and concerns of individuals with lived experience of mental illness by combining photographic images with narrative text (Catalani \& Minkler, 2010; Hergenrather et al., 2009; Wang, Morrel-Samuels, Hutchison, Bell, \& Pestronk, 2004). Photovoice recognizes the insider knowledge of community members that professional experts may lack (Wang \& Burris, 1997) and can shift internal experiences, including an enhanced sense of control over one's life, self-efficacy, self-reflection, self-awareness, and empowerment (Foster-Fishman et al., \& McCann, 2005). Participants are encouraged to engage in critical dialogue with others and to educate non-participants to join in consciousness raising and create social change (Wang \& Pies, 2008). 


\section{Research Context: Imagining Inclusion}

A community-based mental health program in a large city in British Columbia, Canada partnered with a local college to instigate the Imagining Inclusion CBPR project. Front-line recreation therapists initiated this research partnership in order to better understand the lived experience of mental illness and how their interventions could better promote clients' integration and sense of belonging in the community. The research question guiding Imagining Inclusion was: "How do individuals living with mental illness experience community inclusion, health, and well-being?"

The research team comprised two project co-leads, a project manager, two peer researchers, three or four student researchers at a time, and an advisory committee. The peer researchers employed were individuals with lived experience of mental illness and the advisory committee comprised local academics and mental health practitioners who provided conceptual and methodological guidance. The project had a high level of peer participation that began as structured group work and continued past the data-gathering stage into collaborative analysis and knowledge translation. Photovoice comprised the first 10 weeks of data collection and involved 32 research participants. At the last Photovoice session, participants were invited to remain involved as a peer task group (PTG) member. Research team members felt that the sustained involvement of peers in research activities was consistent with the values of CBPR and would provide an opportunity for meaningful engagement and inclusion. Seventeen participants remained involved in the PTGs, which were small working groups that focused on an aspect of knowledge translation from the project including data analysis and photo selection, exhibit planning, newsletter writing, and a speakers' series.

\section{RESEARCH METHODS}

\section{Research Participants}

Upon ethics approval from the Douglas College Research and Ethics Board, research participants were recruited to participate in the study via posters advertising information sessions about the project placed at the community mental health site. Information sessions were held to discuss the project and expectations for involvement. Once prospective participants indicated interest, they were contacted by a member of the research team to ensure that they met the inclusion criteria ${ }^{1}$ and to then arrange an intake interview.

Twenty-three of the 32 participants were women. They ranged in age from 25 to 82 . They were diverse in terms of ethnicity with 19 reporting English as their first language, followed by first languages of Cantonese, Russian, Polish, Ukrainian, and French. Thirteen participants belonged to a visible minority. Twenty-eight participants reported an average annual income of less than $\$ 15,000 \mathrm{CAD}$, which at the time of this study was below the poverty line in British Columbia. Participants reported a range of educational backgrounds, from 10 with a diploma or certificate, 11 with some college or university, and 7 with a university degree. Their diagnosed mental health issues included major depression, bipolar disorder, post-traumatic stress disorder, borderline personality disorder, psychosis, and schizophrenia. The average length of time that participants had spent in the mental health system was 14 years. Most participants reported more than

1. Individuals were eligible to participate if they were over 18 years of age, a client of the community mental health site, and managing medications, addictions, and harmful behaviours. 
one mental health diagnosis, as well as other health issues including addiction, attention deficit disorder, acquired brain injury, and cancer.

\section{Data Collection}

The research question guiding Imagining Inclusion was: "How do individuals living with mental illness experience community inclusion, health, and well-being?" Thirty-two (32) research participants began and completed the Photovoice process; all participants stayed involved for 10 weeks. The first four Photovoice sessions were large group discussions and activities to familiarize participants with the research project, CBPR, Photovoice, research ethics, and the art and technique of photography. For the following five weeks participants photographed their responses to different questions that related to the overarching research question. In these five "photo taking" weeks, the peer researchers facilitated four groups of eight research participants. Together the group explored the guiding questions, then research participants had a week to take photographs in response to the questions and to complete a photo reflection sheet for each photograph. At the next week's meeting, research participants presented their photographs and reflections, which fostered discussion within the small group. All of these discussions were audio recorded. This proved to be an effective way to explore community inclusion, health, well-being and recovery, and to get at some of the challenges and realities of living with a mental illness.

The questions that guided the Photovoice process were intentionally broad so that we could gain a comprehensive understanding of participants' experiences. Sample questions were: What does community mean to you? What do community inclusion and exclusion feel like? What do health and well-being mean to you? What does recovery mean to you? Participants were encouraged to brainstorm their responses to these questions and to imagine metaphors to guide their photo-taking. The final Photovoice session was an evaluation and a celebration.

Ten months after the completion of Photovoice, one-on-one interviews with 14 participants were conducted. The purpose of these interviews was to maintain meaningful involvement and clarify conceptual constructs, such as community, inclusion, and well-being. Overall building community capacity strengthened understanding of experiences of community inclusion, both within the mental health community and in the broader community. The photographs from the Photovoice sessions were not used to guide the interviews.

\section{Data Analysis}

The data set used for this analysis included 25 meeting transcripts and 14 interview transcripts. All data were imported into NVivo10 for analysis. The analysis peer task group met weekly for 18 months and was composed of four research participants, a student researcher, and the project manager. We received ethics approval to engage in collaborative data analysis provided that participants only coded meeting transcripts for meetings where they were present and that participants did not have access to any data between meetings. At these meetings the participant group and academic researchers reviewed and coded excerpts of paper transcripts and discussed overarching themes. Between meetings, the project manager and student researcher transferred the coding into NVivo. The group engaged systematically in inter-rater reliability as they coded collaboratively. 
The coding process had three stages. First, we coded the data descriptively according to the Photovoice questions that were posed. In the next phase we coded the data thematically and identified nine cross-cutting themes: emotional and physical suffering, systems, insecurity, stigma, perseverance, hope, recovery, connection, and tools and strategies. Two of these themes - "recovery" and "tools and strategies" - accounted for approximately one-third of participants' responses that had been coded into the themes (i.e., 204 of 644 coded references).

In the second codebook the recovery and tools and strategies themes broadly referred to the work research participants did to feel better in their day-to-day lives. For most participants, what they did was not framed through the lens of recovery, but rather was understood as strategies for managing their mental health and improving overall health and well-being. Research participants who were active in the analysis process felt strongly that their daily effort - or their "work" - be named and validated. The third codebook comprised a re-coding of the themes of recovery and tools and strategies according to key components and characteristics of health work. It was through this process that the concept of health work emerged from the data and from the research participants' active involvement in the collaborative analysis process. This reflects the praxis orientation of CBPR where data is not removed from persons with lived experience of mental illness. The health work codebook, therefore, enabled our community of researchers to illuminate individuals' varied understandings of health work and to derive a definition of health work based on individuals' lived experiences of mental illness and recovery. Although research participants did not collaborate on this manuscript, Imagining Inclusion research participants and peer researchers actively participated in disseminating the findings through presentations at various conferences, facilitating Photovoice, and public speaking at community events.

In the analysis that follows, pseudonyms are used for all participants. To clarify data sources, "photovoice" indicates a meeting transcript from a Photovoice session and "interview" indicates data from an interview transcript.

\section{RESEARCH FINDINGS: HEALTH WORK AS THE LIVED EXPERIENCE OF DAILY RECOVERIES}

In the Photovoice sessions we spoke at length about the concept of recovery, expectations for recovery, and programs, services, and individuals that had been supportive in the recovery process. As a research team engaged in collaborative analysis, we arrived at the term health work to describe the lived experiences of recovery. Health work is the daily effort involved in the recovery process that is shaped by societal, systemic, and individual factors. As integral to recovery, health work requires effort, is an intentional, lifelong, and precarious process. Individuals engage in health work with the intention to relieve suffering, manage mental illness, gain skills, increase agency and perseverance, and experience connection, belonging, joy, pleasure, and hope. Participants referred to health work as the intentional effort required to achieve "daily recoveries." To honour participants' lived experiences and acknowledge the work they performed, we adopted a frame of health work to portray the fullness and complexity of achieving daily recoveries. 


\section{Health Work Requires Effort}

In conversations about recovery, participants referred repeatedly to the work of recovery and the effort of managing and improving their health and well-being. Most participants spoke directly about their commitment to self-determination, taking responsibility, and having agency and control in their lives, and that maintaining the will to persevere required effort and was, at times, exhausting in the context of living in poverty and facing other systemic and societal barriers. In conversations about recovery, particularly when exploring strategies for visually documenting experiences of recovery as is done in Photovoice, excerpts from participants drew on the metaphors of a journey, a long road or highway, climbing a mountain, and facing closed gates or doors to depict their effort, exertion, and perseverance. For example: "I have to use my effort. Sometimes I have to go uphill or downhill. Sometimes it is not that smooth" (Gemi, photovoice); "my recovery is climbing many mountains, my recovery is like the highway, a road with many, many, many really big potholes. If my recovery could talk, [it would say] 'keep going'" (Keith, photovoice); "the door symbolizes how mental health can be a struggle. In regards to jobs and anything you want to join, and how doors seem to shut on you no matter how much you try" (Sweetie, photovoice); "my recovery is a long road, uphill, with some obstacles, and slow" (Jane, photovoice).

Participants referred to their slow and difficult recovery processes with these metaphors because they faced daily struggles with negotiating healthcare, mental health, employment, and housing systems as well as societal stigma and feelings of exclusion. Natasha said that "it is an uphill battle, it's hard work and you have to fight against strong forces. Like my own lack of confidence, and the experience of being treated badly and misunderstood by others" (photovoice). In conversation some participants even suggested that living in poverty was a tiring layer of "work" they had to do on a daily basis. When Molly Brown ${ }^{2}$ said: "it's kind of a whole skill-set, learning how to deal with poverty. You start to look for all the free things everywhere," Tang responded: "Poverty, it's a big job... to go to different stores to be able to buy what is on sale" (photovoice).

Participants' references to health work included physical activity and leisure activities, such as gardening; having a pet and interacting with animals; listening to music; going to the mall, church, library, or a coffee shop; attending programs; art and the performing arts; cooking and baking; reading and writing; and self-care and therapy. These were health work activities that extended beyond individual self-improvement to gaining connections with others, networking, finding work or volunteering, and enrolling in a training or education program.

Participants also spoke of the mental toll required in coming to terms with their changed status in society. For many, this meant not accomplishing life goals that might have been in place prior to their diagnosis. Molly Brown described her process of coming to terms with her daily effort to feel well and embrace the importance of leisure in her life. She said:

I got sick when I was in university and pushing myself really hard with my schedule. I still feel like I have to be productive all the time. I think that part of my recovery is [like] valuing the things that aren't about being productive. Like sometimes you have to play, and sometimes that's good for your mental health... sometimes I need to let go of producing all the time, and doing, and just see the world in a different way... You have to find things that are meaningful, and I think you have to value different things. It's not always

2. In this instance, "Molly Brown" was the pseudonym chosen by the research participant. 
about getting your paycheck, or getting ahead at work. It's like what makes me feel good, what helps me stay well, valuing those things even if they don't have a tangible outcome. (Molly Brown, photovoice)

In contrast to Molly Brown's deliberate reclamation of the word "work" to describe the daily effort of living with a mental illness, Jane said that recovery was a term that served the needs of her insurance company rather than her own personal needs: "[Recovery means] back to work. You know, that's what my insurance company wants, right? (...) showing up to work every day. Being productive, that stuff" (photovoice). Recovery in this view was tied to economic productivity and not the day-to-day health work that people do to stay well and manage their health. Similarly, Molly Brown's description of leisure as her health work pushed the boundaries of what a narrowly defined recovery-oriented system looks like. The concept of health work for many participants provided an alternative to conceptualizing recovery beyond illness management and economic employment.

\section{Health Work is Intentional}

Participants spoke about how and why they engaged in health work. Their health work activities had a clear purpose and intended outcome. They spoke of engaging in health work to experience a sense of belonging and connection, to feel accepted and cared for, and to feel "known" by someone. Gaining a sense of connection and belonging could bring comfort, support, and feelings of inclusion. For some, health work was about carefully allocating scarce financial resources in order to meet fundamental human needs, such as a need to belong, to connect with others, and to participate in the community around them. Nova, a recent immigrant living on social assistance, described the "socialization fee" that came with frequenting a coffee shop in order to gain a greater sense of inclusion:

I go to this coffee place and read the newspaper while drinking coffee. The owners know me and know which coffee I order. I have acquaintances there. It's like a socialization fee... [The coffee cup] is a symbol of inclusion. Because when I go to that place, I feel included with different people I know. (Nova, photovoice)

Nova allocated some of her meagre resources to pay a socialization fee, indicating both the importance of inclusion and belonging and a belief that there is a cost associated with gaining a sense of belonging.

Participants intentionally focused their health work activities on preventing and managing illness. They spoke about maintaining their health and wellness, preventing and managing physical and mental illness, enhancing mood, experiencing relaxation and healing, and managing their weight. Related to participants' efforts to maintain health and wellness was their desire to relieve their suffering, which they spoke of in terms of overcoming loneliness, decreasing uncertainty, escaping pain, relieving stress, improving sleep, overcoming self-stigma, and reducing medication. Molly Brown said:

Being active helps me feel like I can handle life, solve my problems. It helps move me when I'm "stuck," mentally or emotionally. It helps my mental health, gives me a sense of mastery, makes me feel normal.

Doing exercise together helps me connect with people both in and out of the mental health system. It has been a huge contributor to my recovery. (Molly Brown, photovoice)

Participants' profound experiences of mental illness and suffering encouraged some to pursue avenues for personal growth. Personal growth entailed increasing confidence and self-esteem, nurturing oneself to meet deeper spiritual needs, and gaining a sense of self-acceptance. 
Finally, participants engaged in health work to gain a sense of purpose, fulfilment, contribution, meaning, and progress.

It's really important to have connection with others... and that's a double-edged sword because it's what you experience and learn from others, but it's also what you can give back... for me it's really important to feel like I can make a difference in some small way. (Daphne, interview)

Another participant extended her health work to advocacy efforts. Sweetie said, "Now I feel like I could voice my opinion and tell people certain things about myself and not feel regretful. I find talking about my mental illness actually makes me feel good... it just relieves all that" (Sweety, interview). The broad range of research participants' health work activities - from those that were individually focused to advocacydemonstrates both their agency and intention in engaging in activities to manage their own health and to make a contribution to the community.

\section{Health Work is Lifelong}

The majority of respondents did not view recovery as a health outcome. Most suggested that their mental illness was lifelong and therefore health work was a daily act to manage and promote well-being over their life course. Iris said: "I don't really think of the word recovery. For me it's ongoing" (interview). Another participant criticized the concept of recovery for setting up an expectation of recovering from, or no longer having, a mental illness: “It says [on worksheet] 'what or who have played a role in my recovery'? That's very positive, but I am not really expecting to recover. Like with disabilities, do you know what I am saying?" (Caren, photovoice). Clear Mirror suggested that the terms "health and well-being" were more personally meaningful and realistic. He said:

It's my health or well-being rather than my recovery.... Recovery is the ideal; it's kind of like Dorothy in Wizard of $\mathrm{Oz}$. She meets the $\mathrm{Oz}$ and sees that the $\mathrm{Oz}$ is just smoke and mirrors. It's about being accountable in the present; there's no such thing as I'm going to get well, get a job, live on the west side, and so that's the analogy. Oz is the word recovery... It's the pie in the sky, it's not real, it's not going to happen.... However, I recover three to four times a week, where I need to be isolated to be safe enough to then venture out. So, I'm accustomed to it as a method of coping, an everyday thing. I don't look at the end of the eight hours isolated when the fear and terror are all gone, I feel as good as possible. These are my recoveries. (Clear Mirror, interview)

In this and other critiques of recovery participants suggested that the work was ongoing and day to day, rather than having an end point.

\section{Health Work is Precarious}

While individuals' health work activities were intentional in their day-to-day life, health work was often challenged by individuals' mental health symptoms and by broader societal and systemic factors. Barriers to doing the day-to-day work of recovery were described by all participants as not having physical and material needs met, such as income, housing, transportation, and food security. Participants also spoke of systemic barriers related to health work such as engaging with income assistance, government-subsidized housing, and employment insurance. Daphne said: "I find my recovery to be a real challenge with regards to finding the right balance between healthy eating, relaxation, sleep, activity, socializing, community involvement, and 
negotiating the healthcare and social systems" (interview). Perlita used the metaphor of going "downhill," in contrast to the recovery metaphor of climbing or cycling uphill, to speak about the challenges to engaging in health work. Perlita said:

In my life, the chaos was there. There was this little part of me trying to get well and this other part of me trying to deal with... just to get through, you know, some things that you take for granted now. When you just don't have all your faculties, all your confidence, all your self-esteem... it's hard work and when you don't have a lot of energy, you don't sleep well, so everything is just down and down and down. (photovoice)

Both Daphne and Perlita's comments emphasized the precariousness of stable mental health and health work. When discussing efforts to feel well, Iris explained that she hoped to have a greater purpose despite having to struggle to meet her basic needs:

It's more than food and the basics to keep the body functioning. I use the word nurture, and it's the only way I can explain it in words, to keep me going and keep me alive and the strength to keep going each day [crying]. And you're not really having a purpose, you're working to have income to keep going and besides the basics - shelter and food and clothing - besides that to be able to have those choices. So, a person can think "well what value do I have now? What can I contribute to society now and to keep me going each day?" (Iris, interview)

Mark used the metaphor of "many battles" to connote his health work:

Just seeing one lonely leaf left on that tree made me think of survival and how so many of us in the mental health system have to go through many battles for survival. That's the first thing that I thought when I saw one lonely leaf that's likely never fallen off that tree for the entire fall and well into winter season now that it's late February. But yet at the same it represents human characteristics of persistence, perseverance and yet it can also mean the exact opposite that I am all alone, there is nobody around to support me. (photovoice)

Engaging in health work forced participants to take risks and responsibility, make choices, and face internal fears such as self-doubt and low confidence and external challenges including accessing services and supports to promote recovery through health work. Participants' health work was neither assured nor taken for granted; rather, it resided in a precarious and tenuous balance that intersected micro- and macro-level factors.

\section{DISCUSSION}

What was revealed in this analysis was that the current "enactment" of recovery through mainstream recovery-oriented practice neither reflects nor adequately responds to individuals' experiences and needs. Recovery enactments continue to emphasize empowerment, agency, and hope (Weiser et al., 2011) with little attention to the social structures that produce, and in some cases, reinforce marginalization and stigmatization of mental illness (Howell \& Voronka, 2012; McWade, 2016; Morrow, 2013; Rose, 2014). The concept of health work, as applied in this analysis, responds to these gaps by shedding light on the social determinants of recovery and personal lived experiences of mental illness, both of which are cornerstones of MHCC strategy (Chodos et al., 2015; Lucock et al., 2011; MHCC, 2016). Importantly, our collaborative approach to data analysis validated the construct of health work as a daily process and was seen as empowering by the research participants. Since the concept of health work affirms and validates the work and challenges of living with a mental illness, it reframes unrealistic ideals of autonomy, choice, hope, and self-management 
that are promoted by the mental health system under the umbrella of recovery (McWade, 2016), and challenges perceptions of individuals with mental illness as deviant, lazy, disengaged, and burdensome.

Individuals living with mental illness engage in day-to-day work in order to promote and maintain their health (Lucock et al., 2011) and have multiple interpretations of recovery (Morrow \& Weisser, 2012). Through engaging in collaborative data analysis, researchers and research participants together identified the concept of health work to represent the intentional daily effort of living with a mental illness and the precariousness of the recovery process. Participants indicated that health work was shaped by societal, systemic, and individual factors, required effort, and was an intentional, lifelong, and precarious process. They affirmed that health work reflected the fullness and complexity of their work in striving for daily recoveries. This finding is consistent with Karban (2017) who argues that there is a need to contextualize recovery from the perspective of people experiencing mental health challenges in relation to broader structural policies and practices.

Little attention has been paid to the social determinants of mental health and their impact on individual lived realities (Hyde et al., 2015; Luckock et al., 2011; Morrow \& Weisser, 2012). Central characteristics of health work are that it is precarious, life long, and requires diligence and support. Individuals with lived experience of mental illness are vulnerable disproportionately to the negative effects of the social determinants of mental health, such as social exclusion, stigma, and discrimination. These experiences play out in their pursuit of health work. Health work, much like mental health, is a dynamic experience that is shaped by the social, economic, and physical environments in which people live (Fisher \& Baum, 2010; WHO, 2014).

Importantly, the concept of health work has implications for equitable recovery-oriented policy and practice. Understanding the lived experience of recovery through the lens of health work suggests that individuals with mental illness need a wide range of supports and services in order to live a full life to maximize their potential for recovery (Trainor, Pomeroy, \& Pape, 2004). Understanding health work as an integral component of recovery can inform recovery-oriented practices by providing a more complex understanding of the core concepts of the recovery movement and by exposing the role of social and institutional structures in shaping lived experience of agency, self-determination, empowerment, and hope. This will improve individual outcomes by facilitating "daily recoveries" in ways that are personally meaningful, that acknowledge barriers encountered, and that help mental health services to critically evaluate their own role in supporting and inhibiting lived experience of recovery. Moreover, embracing health work can make visible individual capacities and de-stigmatize mental illness, which are at the heart of the recovery movement. To this end current research findings forge new ground in conceptualizations and applications of recovery by focusing on the intersection of micro (individual experience) and macro (system barriers) processes.

The concept of health work provides greater understanding of the lived experience of recovery by making the effort or work of living with mental illness visible. It allows people to feel pride in doing the work of recovery and that the truth and fullness of their lived experience are acknowledged and better understood. It also illuminates the financial, personal, and social costs of mental illness and the daily suffering endured. Finally, health work allows for service providers to better facilitate and support individuals' mental health. This can illuminate important yet overlooked components of mental healthcare planning such as friendships and social connections, leisure activities, and peer support. As May et al., (2014) argue "[The] exercise of agency is constrained by controls on service content and the distribution of opportunities for care, and by the social and economic resources available to participants" (p. 287). The integration of health work into 
recovery-oriented practice will foster more appropriate and effective service utilization, allow for greater social inclusion, and facilitate health and healing.

\section{RECOMMENDATIONS FOR POLICY AND PRACTICE}

In the community mental health system, it is relatively well-known that individuals with lived experience of mental illness suffer disproportionately from the social determinants of mental health. It is also generally accepted that there is little a front line service provider or practitioner can do to address the social determinants of mental health. Rather than seeing the "solution" in isolation, it is the responsibility of all levels of the mental health system - from front line practitioner to senior management - to recognize the pervasiveness of the social determinants of mental health and to begin to address the fundamental inequities through the ongoing support for, and promotion of, health work. These recommendations are consistent with the need for better integration of the social determinants of health within and across all levels of service sectors including mainstream mental health services (WHO, 2014).

Moving forward, strategies to redress inequities and promote inclusive mental health policy and practice must recognize that individuals with lived experience of mental illness are continually engaging in health work. Health work can take different forms depending on mental health diagnosis as well as broader social and structural processes that impact levels of support and stability with mental health. A recovery-oriented mental health system that embraces health work can be accomplished by: (1) recognizing, learning from, and supporting the ongoing health work efforts of people living with mental illness; (2) providing mental health services and programs that have opportunities for sharing experiences, networking, advocacy, and making a contribution; (3) integrating strategies for voicing the lived experience of mental illness into service delivery so the fullness of individuals' lived experience-including the social determinants of their mental health - can be heard; and (4) devising recovery-oriented policies and practices that take aim at the broader social determinants of mental health that profoundly affect the lived experiences of mental illness and that can combat the stigma of mental illness. If we are to truly operationalize recovery-oriented practice as the framework for mental health and well-being in Canada, then we must acknowledge the significance of health work in the lives of individuals with mental illness. This involves critically reflecting on the practices that constrain the recovery process and challenging exclusionary values and attitudes that construct recovery as personal journeys unencumbered by social and systemic barriers.

\section{REFERENCES}

Anthony, W. (1993). The guiding vision of the mental health service system in the 1990s. Psychosocial Rehabilitation Journal, 16(4), 11-23.

Barnett, E., \& Casper, M. (2001). A definition of "social environment". American Journal of Public Health, 91(3), 465a-465. doi-org.ezproxy.library.uvic.ca/10.2105/AJPH.91.3.465a

Belle-Isle, L., Benoit, C., \& Pauly, B. (2014). Addressing health inequities through social inclusion: The role of community organizations. Action Research, 12(2), 177-193. doi:10.1177/1476750314527324

Borg, M., \& Davidson, L. (2008). The nature of recovery as lived in everyday experience. Journal of Mental Health, 17(2), 129-140. doi:10.1080/09638230701498382

Borg, M., Karlsson, B., Tondora, J., \& Davidson, L. (2009). Implementing person-centered care in psychiatric rehabilitation: What does this involve? The Israel Journal of Psychiatry and Related Sciences, 46(2), 84-93. 
Burns, J. K., Tomita, A. \& Kapadia, A. S. (2014). Income inequality and schizophrenia: Increased schizophrenia incidence in countries with high levels of income inequality. International Journal of Social Psychiatry, 60(2), 185-96. doi:10.1177/0020764013481426

Burrill, E. (1998). Health conception, health work and health-promoting lifestyle practices in Latin American Mennonite families. Unpublished master's thesis, University of Western Ontario, London, Ontario, Canada.

Catalani, C., \& Minkler, M. (2010). Photovoice: A review of the literature in health and public health. Health Education \& Behavior, 37(3), 424-451.

Chodos, H., d'Auteuil, S., Martin, N., \& Raymond, G. (2015). Guidelines for recovery-oriented practice: Hope. dignity. inclusion. Ottawa, ON: Mental Health Commission of Canada.

Davidson, L., Lawless, M. S., \& Leary, F. (2005). Concepts of recovery: Competing or complementary? Current Opinion in Psychiatry, 18(6), 664-667.

Deegan, P. E. (1988). Recovery: The lived experience of rehabilitation. Psychosocial Rehabilitation Journal, 11(4), 11-19. doi:10.1037/h0099565

Fisher, M., \& Baum, F. (2010). The social determinants of mental health: Implications for research and health promotion. Australia and New Zealand Journal of Psychiatry, 44(12), 1057-63. doi:10.3109/00048674.2010.509311

Flicker, S., Savan, B., McGrath, M., Kolenda, B., \& Mildenberger, M. (2008). 'If you could change one thing...'What community based researchers wished they could have done differently. Community Development Journal, 43(2), 239-253. doi:10.1093/cdj/bsm009

Ford-Gilboe, M. (1997). Family strengths, motivation and resources as predictors of health promotion behaviour in single-parent and two-parent families. Research in Nursing \& Health, 20(3), 205-17. doi:10.1002/ (sici)1098-240x(199706)20:3<205::aid-nur4>3.0.co;2-m

Foster-Fishman P., Nowell B., Deacon Z., Nievar M. A., \& McCann P. (2005). Using methods that matter: The impact of reflection, dialogue, and voice. American Journal of Community Psychology, 36(3-4), 275-91. doi:10.1007/ s10464-005-8626-y

Hergenrather, K. C., Rhodes, S. D., Cowan, C. A., Bardhoshi, G., \& Pula, S. (2009). Photovoice as community-based participatory research: A qualitative review. American Journal of Health Behavior, 33(6), 686-98. doi: $\underline{\text { ttps:// }}$ doi-org.ezproxy.library.ubc.ca/10.5993/AJHB.33.6.6

Howell, A., \& Voronka, J. (2012). Introduction: The politics of resilience and recovery in mental health care. Studies in Social Justice, 6(1), 1-7.

Hyde, B., Bowles, W., \& Pawar, M. (2015). 'We're Still in There'_Consumer voices on mental health inpatient care: Social work research highlighting lessons for recovery practice. British Journal of Social Work, 45(Supplement 1), i62-i78. doi:10.1093/bjsw/bcv093

Karban, K. (2017). Limitations of individualized recovery discourse. Developing a health inequalities approach for mental health social work. British Journal of Social Work, 47(3), 885-992. doi:10.1093/bjsw/bcw098

Lucock, M., Gillard, S., Adams, K., Simons, L., White, R., \& Edwards, C. (2011). Self-care in mental health services: A narrative review. Health and Social Care in the Community, 19(6), 602-616. doi:10.1111/j.1365-2524.2011.01014.x

May, C. R., Eton, D. T., Boehmer, K., Gallacher, K., Hunt, K., MacDonald, S. ... Shippee, N. (2014). Rethinking the patient: Using Burden of Treatment Theory to understand the changing dynamics of illness. BMC Health Services Research, 142(81). doi:10.1186/1472-6963-14-281

McWade, B. (2016). Recovery-as-policy as a form of neoliberal statemaking. Intersectionalities: A Global Journal of Social Work Analysis, Research, Polity, and Practice, 5(3), 62-81.

Mental Health Commission of Canada, Centre for Addiction and Mental Health. (2009). Improving mental health services for immigrant, refugee, ethno-cultural and racialized groups: Issues and options for service improvement. Retrieved from http:/www.mentalhealth commission.ca/SiteCollection Documents/KeyDocuments/en/ 2010/ IssuesoptionsFINALEnglish 902012NOV09.pdf

Mental Health Commission of Canada. (2012). Changing directions, changing lives: The mental health strategy for Canada. Calgary, Alberta, Canada: Author

Mental Health Commission of Canada (MHCC). (2016a). The Case for Diversity: Building the Case to Improve Mental Health Services for Immigrant, Refugee, Ethno-cultural and Racialized Populations, Ottawa, ON: Mental Health Commission of Canada. Retrieved from http://www.mentalhealthcommission.ca 
Mental Health Commission of Canada (MHCC). (2016b). Mental Health Commission of Canada-Strategic Plan 2017-2022, Ottawa, ON.

Mental Health Commission of Canada (MHCC). (2019). Immigrant, refugee, ethnocultural and racialized populations and the social determinants of health-A review of 2016 Census Data, Ottawa, ON: Mental Health Commission of Canada. Retrieved from http://www.mentalhealthcommission.cahttp://www.mentalhealthcommission.ca

Mezzina, R., Borg, M., Marin, I., Sells, D., Topor, A., \& Davidson, L. (2006). From participation to citizenship: How to regain a role, a status, and a life in the process of recovery. American Journal of Psychiatric Rehabilitation, 9(1), 39-61. doi:10.1080/15487760500339428

Morrow, M. (2013). Recovery: Progressive paradigm or neoliberal smokescreen? In B. A. LeFrançois, R. Menzies, \& G. Reaume (Eds.), Mad matters: A critical reader in Canadian Mad Studies (pp. 323-333). Toronto, ON: Canadian Scholars' Press.

Morrow, M., \& Weisser, J. (2012). Towards a social justice framework of mental health recovery. Studies in Social Justice, 6(1), 27-43.

Pauly, B., Carlson, E., \& Perkin, K. (2012): Strategies to end homelessness: Current approaches to evaluation. Toronto: Canadian Homelessness Research Network Press

Provencher, H. L. \& Keyes, C. L. M. (2011). Complete mental health recovery: Bridging mental illness with positive mental health. Journal of Public Mental Health, 10(1), 57-69. doi.org/10.1108/17465721111134556

Reid, C., Brief, E., \& LeDrew, R. (2009). Our Common Ground: Cultivating Women's Health Through Community Based Research. Vancouver BC: Women's Health Research Network.

Reid, C., \& Brief, E. (2009). Confronting condescending ethics: How community based research challenges traditional approaches to consent, confidentiality, and capacity. Journal of Academic Ethics, 7, 75-85. doi:10.1007/ s10805-009-9085-0

Roberts, G., \& Wolfson, P. (2004). The rediscovery of recovery: Open to all. Advances in Psychiatric Treatment, 10(1), $37-48$.

Rossiter, K., \& Morrow, M. (2011). Intersectional frameworks in mental health: Moving from theory to practice. Health Inequities in Canada: Intersectional Frameworks and Practices, 312-330.

Rose, D. (2014). The mainstreaming of recovery. Journal of Mental Health, 23(5), 217-218. doi:10.3109/09638237. 2014.928406

Schön, U., Denhov, A., \& Topor, A. (2009). Social relationships as a decisive factor in recovering from severe mental illness. The International Journal of Social Psychiatry, 55(4), 336-347. doi:10.1177/0020764008093686

Tew, J., Ramon, S., Slade, M., Bird, V., Melton, J., \& LeBoutillier, C. (2012). Social factors and recovery from mental health difficulties: A review of the evidence. British Journal of Social Work, 42, 443-460. doi:org.ezproxy.library. ubc.ca/10.1093/bjsw/bcr076

Topor, A., Borg, M., Di Girolamo, S., \& Davidson, L. (2011). Not just an individual journey: Social aspects of recovery. The International Journal of Social Psychiatry, 57(1), 90-99. doi:10.1177/0020764010345062

Topor, A., Borg, M., Mezzina, R., Sells, D., Marin, I., \& Davidson, L. (2006). Others: The role of family, friends, and professionals in the recovery process. American Journal of Psychiatric Rehabilitation, 9(1), 17-37. doi: $10.1080 / 15487760500339410$

Trainor, J., Pomeroy, E., \& Pape, B. (2004). A Framework for Support: 3rd Edition. Canadian Mental Health Association, Toronto, 2004. https://cmha.bc.ca/wp-content/uploads/2015/11/Framework_for_Support.pdf

Webb, L. (2012). The recovery model and complex health needs: What health psychology can learn from mental health and substance misuse service provision. Journal of Health Psychology, Jul; 17(5): 731-741. Published online 2011 Oct 21. doi: 10.1177/1359105311425276

Wang C., \& Burris, M. A. (1997). Photovoice: Concept, methodology, and use for participatory needs assessment. Health Education Behavior, 24(3), 369-87. doi:10.1177/109019819702400309

Wang C., Morrel-Samuels, S., Hutchinson, P. M., Bell, L., \& Pestronk, R. M. (2004). Flint Photovoice: Community building among youths, adults and policymakers. American Journal of Public Health, 94(6), 911-913.

Wang, C. C., \& Pies, C. A. (2008). Using Photovoice for participatory assessment and issue selection: Lessons from a family, maternal, and child health department. In M. Minkler \& N. Wallerstein (Eds.), Community-based participatory research for health: From process to outcomes (pp.183-197). San Francisco, CA: Jossey-Bass. 
Weisser, J., Morrow, M., \& Jamer, B. (2011). A critical exploration of social inequities in the mental health recovery literature. Vancouver, BC: Centre for the Study of Gender, Social Inequities and Mental Health (CGSM). http:// www.socialinequities.ca

Wilton, R. (2004). Putting policy into practice? Poverty and people with serious mental illness. Social Science \& Medicine (1982), 58(1), 25-39.

World Health Organisation (WHO). (2014). Social determinants of mental health. Geneva, World Health Organisation. 